\title{
Surgical Management of Postinfarction Ventricular Septal Defect
}

\author{
Gösta Pettersson \\ Department of Thoracic and Cardiovascular Surgery, The Cleveland Clinic Foundation, Cleveland, Ohio, USA
}

In this issue of Heart Drug, Prêtre and Turina [1] present a retrospective study of 54 patients operated on for postinfarction ventricular septal defect (VSD) during the period 1979-1998. The treatment protocol applied was based on the principles of early closure, concomitant myocardial revascularization and ventricular remodeling.

In the late 1970s, Daggett et al. [2] and Daggett [3, 4] outlined the principles for the surgical treatment of postinfarction VSDs. Although surgical results have improved over time, postinfarction VSD still represents a great challenge, as illustrated by the early mortality rate of over $20 \%$ in the paper in this issue [1] during the last decade. These patients often come out of the operating room on maximal support and have a long and difficult course in the intensive care unit. There are no randomized studies and no studies in which all patients with a postinfarction VSD from a given population have been entered to give a true picture of the spectrum of the problems and issues. We are limited to retrospective studies of patients who, for one reason or another, were operated on for their VSD. The patient selection is based on the biases of the involved cardiologists and surgeons. Important risk factors may be masked by selection criteria not accounted for.

The development of treatment strategies and surgical techniques to deal with postinfarction VSDs is based on the application of experience and technologies which have been slowly developed over time. Some of them have been used and tested in other more prevalent patient groups (the 'grounded theory' approach to development). The numbers in all series are small (the Cleveland Clinic 1969-2000 series of postinfarction VSDs included 130 patients [5]) and the selection process and criteria as well as level of surgical experience are different in each series.

Patient selection is of primary importance to the outcome: which patients with a postinfarction VSD should be operated on? The spectrum includes younger patients with limited myocardial damage and small VSDs as well as older patients in cardiogenic shock and renal and other organ failure. In a recent, not yet published analysis of 130 patients operated on for postinfarction VSD between 1969 and 2000 at the Cleveland Clinic, the risk factors for death included older age $(p=0.006)$, anuria $(p=0.02)$, shorter interval from myocardial infarction to surgery $(p<0.0001)$, residual shunt $(p<0.0001)$ and earlier era of surgery $(p<0.0001)$ [5]. Using a multivariable hazard function equation, a subset of high-risk patients (short interval between infarct and surgery, anuria, severe right ventricular dysfunction) was identified for whom surgical therapy was associated with excessive hospital mortality $(75 \%)$ and no survivors beyond 3 years. For these patients, surgery should not be offered as a therapeutic option. With the best constellation of risk factors, a moderate interval between myocardial infarction and surgery and the absence of other risk factors, 3-year survival was

\section{KARGER \\ Fax +41613061234 \\ E-Mail karger@karger.ch \\ www. karger.com

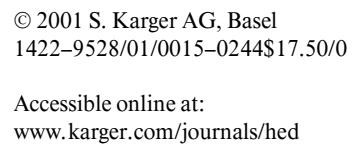

Dr. Gösta Pettersson

Department of Thoracic Surgery

Cleveland Clinic Foundation, Heart Center

9500 Euclid Avenue, Cleveland, OH 44195 (USA)

Tel. +1 216444 2035, Fax +1 216444 6697, E-Mail petterg@ccf.org 
$80 \%$. Early risk and long-term outcome did go hand in hand. The importance of right ventricular failure to the outcome is well recognized [6]. Among the patients in the report of Prêtre and Turina [1], 46\% were considered to be in shock and 57 were supported by intraaortic balloon pump at the time they were taken to surgery. Additional information to estimate the risk was not provided. A patient selection resulting in less than $20-25 \%$ mortality and 50-65\% 5-year survival, however, is definitely acceptable. To obtain these results, the patients with the highest risk and worst prognosis have to be identified and not offered surgery. The paper by Pretre and Turina [1] does not discuss the selection process and criteria employed. Although it is a risk factor, age alone does not disqualify the patient for surgery [7].

Is early surgery the optimal approach in all patients? Early surgery is technically very demanding, depending on poor tissue quality. Early surgery is associated with a high incidence (10\% in the report of Prêtre and Turina [1] is to be considered a low incidence; it was $40 \%$ in another recent paper by Deja et al. [8]) of residual shunts. Defining the margins of the infarct is a problem. Designing and suturing the patch is another. Posterior VSDs are technically more difficult to operate. Postponing surgery in patients with large shunts results in clinical deterioration, with the development of pulmonary congestion, right ventricular failure, falling cardiac output and eventually cardiogenic shock with multiorgan failure. The old strategy was to manage postinfarction VSD patients medically and, when needed, with an intraaortic balloon pump for 3-4 weeks before operating to allow the VSD to define itself and the infarct to be replaced with a fibrous scar. This strategy selects out the hardiest $20 \%$ of the patients. The patients who tolerate this treatment strategy could be operated on with good results at any time and a few may even survive without surgery. The contribution of Daggett $[3,4]$ and Daggett et al. [2] was to develop surgical techniques to successfully deal with postinfarction VSDs in the acute early phase. To reduce the risk of residual shunts, David et al. [9] favor the use of pericardium sutured to the myocardium all around the infarct, excluding the infarct. The pericardium is softer and more compliant, and covering a larger area of myocardium reduces the stress on the sutures.

Posterior infarction is sometimes associated with important mitral valve regurgitation, and in these cases, valve replacement rather than repair may be necessary.

Prêtre and Turina [1] introduce the concept of ventricular remodeling to deal with secondary changes in the ventricle. The principles of surgical repair of postinfarc- tion VSD outlined by Daggett et al. [2] aimed at restoring the normal ventricular configuration. Most often, a left ventricular aneurysm is dealt with as part of the operation. Although possibly theoretically interesting, the scenarios where additional remodeling or addition of remodeling or not would make a difference are difficult to imagine, knowing there is a risk of residual shunt of $10-40 \%$. The use of a pericardial patch for the repair favors safe repair and a low risk of residual shunt over the concept of ventricular remodeling.

The value of coronary artery bypass grafting at the time of repair of a postinfarct VSD remains controversial. All these patients have coronary artery disease, but the disease may well be limited to the artery going to the area of infarct, the culprit artery. In VSD cases, the infarct is transmural and reperfusion of the culprit artery will do little or no good. The question is rather related to the probability of finding additional coronary stenoses to graft versus the risk of catheterization (mainly delay of the operation and renal failure). Once identified, the risk of grafting does not justify ignoring significant stenoses in coronary arteries to viable myocardium. In the series of Prêtre and Turina [1], patients without additional coronary artery disease did somewhat better than those with, but this does not help us in our decision making regarding the indications for heart catheterization and coronary artery bypass grafting. If coronary bypass grafting had not been performed, the difference could have been even more pronounced. Muehrcke et al. [10] found that bypassing associated coronary artery disease significantly increased long-term survival when compared with patients with unbypassed coronary artery disease. However, Dalrymple-Hay et al. [11] were unable to confirm early mortality or long-term survival benefits from concomitant coronary bypass grafting.

The surgeons have to share with the cardiologists, anesthesiologists and intensivists the credit for the improved results over time and the improved pre-, intra- and postoperative management of these very sick patients. Preoperatively, the goals of the treatment are to limit the infarct size and to prevent secondary organ failure. The intraaortic balloon pump has a central position in the management of this patient group both before and after surgery.

Prêtre and Turina [1] must be congratulated on their excellent results. Even though not all patients benefited from surgery, we have to be active in improving our understanding of the issues and continuing to make progress. The papers referred to in this editorial, as well as many others, have shown good long-term outcomes for the operative survivors. 


\section{References}

1 Prêtre R, Turina MI: Surgical management of postinfarction ventricular septal rupture. Heart Drug 2001;1:255-259.

2 Daggett WM, Burwell LR, Lawson DW, Austen WG: Resection of acute ventricular aneurysm and ruptured interventricular septum after myocardial infarction. N Engl J Med 1970; 283:1507-1508

3 Daggett WM: Postinfarction ventricular septal defect repair: Retrospective thoughts and historical perspectives. Ann Thorac Surg 1990;50. 1006-1009.

4 Daggett W: Surgical technique for early repair of posterior ventricular septal rupture: Importance of rupture location. Ann Thorac Surg 1996;61:1752-1758.
5 Lam B-K, Blackstone EH, Gillinov AM, Lytle BW, Cosgrove DM III: Postinfarct VSD: For whom is operation futile? Abstract to The Canadian Cardiovascular Society, Halifax, October 2001.

6 Angelini GD, Penny WJ, Ruttley MS, Butchart EG, West RR, Henderson AH, Breckenridge IM: Post-infarction ventricular septal defect: The importance of right ventricular coronary perfusion in determining surgical outcome. Eur J Cardiothorac Surg 1989;3:156-161.

7 Muehrcke DD, Blank S, Daggett WM: Survival after repair of postinfarction ventricular septal defects in patients over the age of 70 . J Card Surg 1992;7:290-300.

8 Deja MA, Szostek J, Widenka K, Szafron B, Spyt TJ, Hickey MS, Sosnowski AW: Post infarction ventricular septal defect - can we do better? Eur J Cardiothorac Surg 2000;18:194201.
9 David TE, Dale L, Sun Z: Postinfarction ventricular septal rupture: Repair by endocardial patch with infarct exclusion. J Thorac Cardiovasc Surg 1995;110:1315-1322.

10 Muehrcke DD, Daggett WM Jr, Buckley MJ, Akins CW, Hilgenberg AD, Austen WG: Postinfarct ventricular septal defect repair: Effect of coronary artery bypass grafting. Ann Thorac Surg 1992;54:876-882.

11 Dalrymple-Hay MJ, Langley SM, Sami SA Haw M, Allen SM, Livesey SA, Lamb RK, Monro JL: Should coronary artery bypass grafting be performed at the same time as repair of a post-infarct ventricular septal defect? Eur J Cardiothorac Surg 1998;13:286-292. 